\title{
Characterization of directionally recrystallized cold-rolled nickel using EBSP
}

\author{
B. Iliescu, J. Li and I. Baker
}

Thayer School of Engineering, Dartmouth College, Hanover, NH 03755, USA

Scanning electron microscopy (SEM) and electron back-scattered diffraction patterns (EBSP) have been employed to investigate the changes in the microstructure and texture of $90 \%$ cold-rolled nickel when subjected to directional recrystallization. The effects of annealing temperature, hot zone velocity, and temperature gradient ahead of the hot zone on the microstructure were investigated.

Specimens roughly $10 \mathrm{~mm} \times 10 \mathrm{~mm} \times 100 \mathrm{~mm}$ in size were produced from polycrystalline nickel and cold rolled to $90 \%$ thickness reduction. Directional recrystallization experiments were carried out in air using a home-built furnace. The specimens were held stationary and the furnace and associated cooling plates were translated together by a stepper motor. The translation velocities can be varied between $2 \mathrm{~mm} / \mathrm{h}$ and $600 \mathrm{~mm} / \mathrm{h}$. The temperature gradient ahead of the hot zone is controlled by changing the used distance between the cooling plates and the top of the furnace. The temperature gradient was $\sim 270^{\circ} \mathrm{C} / \mathrm{cm}$. Experiments were conducted with two hot zone temperatures $\left(370^{\circ} \mathrm{C}\right.$ and $470^{\circ} \mathrm{C}$, respectively) and three hot zone velocities $(4.5 \mathrm{~mm} / \mathrm{h}, 40 \mathrm{~mm} / \mathrm{h}$ and $50 \mathrm{~mm} / \mathrm{h})$. Microstructural changes in the specimens were investigated using a Zeiss DSM962 scanning electron microscope equipped with an EBSP system operated at $30 \mathrm{KeV}$. Prior to examination in the SEM the specimen surfaces were mechanically polished and electropolished in a solution containing $14 \%$ sulfuric acid, $71 \%$ phosphoric acid and $0.75 \%$ hydrochloric acid in water at $+45^{\circ} \mathrm{C}$. Backscattered electron images were also acquired.

SEM/EBSP examinations of nickel in "as received" condition showed that prior to rolling a largely random texture was present. Upon cold rolling however, the nickel developed the texture shown in Figure 1. An orientation map of a cold-rolled nickel specimen subjected to directional recrystallization is shown in Figure 2. The green shades indicate grains within which the $<001>$ crystallographic direction lies parallel to the rolling direction. They make up approximately $70 \%$ of the total area investigated. Grains marked in red exhibited large deviations of the $<001\rangle$ direction from the rolling direction. The alignment of the $\langle 100\rangle$ axes with the rolling direction after directional recrystallization is visible in the contoured pole figure in Figure 3. The cube-texture is typical and was observed for all annealing temperature - hot zone velocity combinations investigated. After directional recrystallization, the specimens exhibited in general smaller average grain sizes (between $12 \mu \mathrm{m}$ and $18 \mu \mathrm{m}$ ) compared to "as-received" condition which had an average grain size of $\sim 21 \mu \mathrm{m}$. The only exception was the extreme case of $\mathrm{T}=470^{\circ} \mathrm{C}$ and $\mathrm{V}=4.5 \mathrm{~mm} / \mathrm{h}$ where the average grain size remained practically unchanged $(\sim 22 \mu \mathrm{m})$ after directional recrystallization.

In conclusion, directional recrystallization of cold-rolled nickel leads to the formation of a strong cube-texture with the $<100>$ axes aligned parallel to the rolling direction.

This work was supported by National Science Foundation grant DMI-9976509 and the Air Force Office of Scientific Research, USAF, under grant number F 49620-00-1-0076. The views and conclusions contained herein are those of the authors and should not be interpreted as necessarily 
representing official policies, either expressed or implied, of the Air Force Office of Scientific Research or the U.S. Government.
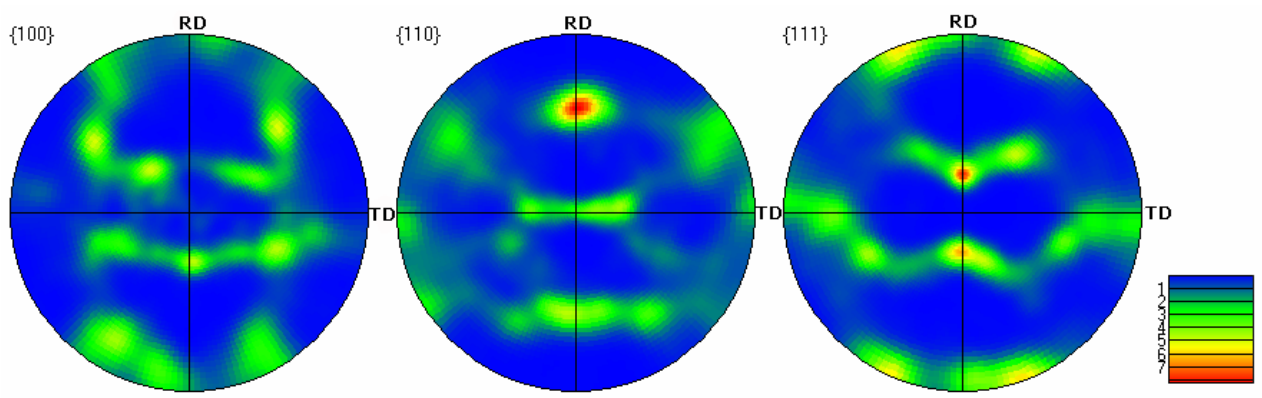

FIG. 1 Contoured pole figures of the rolling texture of nickel rolled to a reduction of $90 \%$. The normal to the rolling plane is at the center. RD represents the rolling direction. The legend indicates the probability (frequency) of a certain orientation of a particular crystallographic axis.

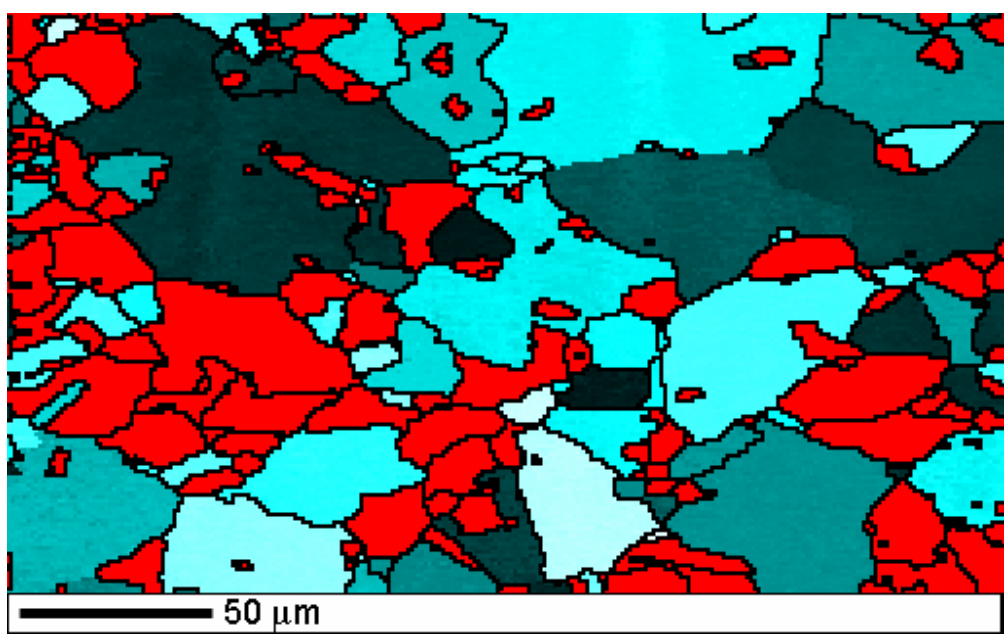

FIG. 2. Orientation map obtained by EBSP analysis of cold-rolled nickel, directionally recrystallized at $\mathrm{T}=370^{\circ} \mathrm{C}$ and velocity $40 \mathrm{~mm} / \mathrm{h}$. The rolling direction (RD) is orizontal. The grain boundaries were established by the EBSP system based on a $10^{\circ}$ misorientation angle.
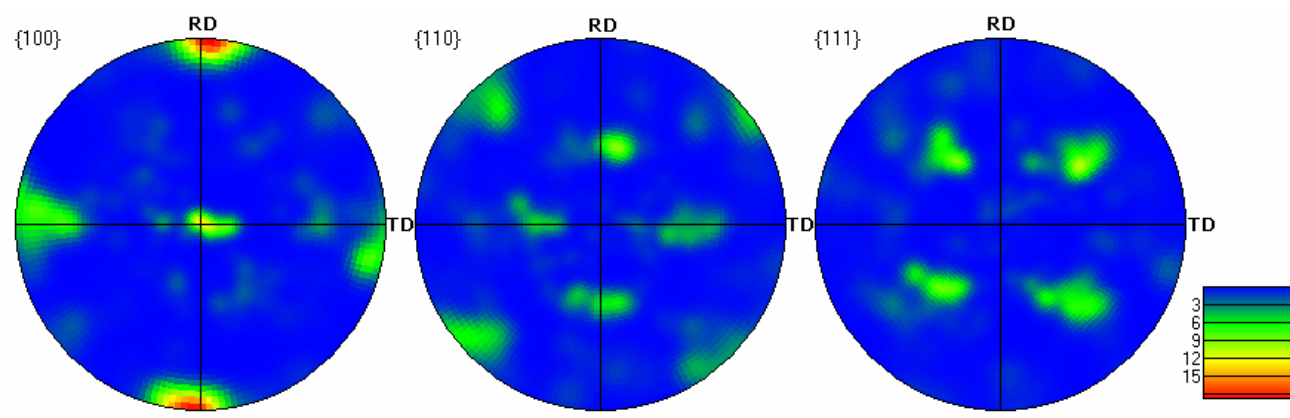

FIG. 3 Contoured pole figures showing the annealing textures of cold-rolled nickel, directionally recrystallized at $\mathrm{T}=370^{\circ} \mathrm{C}$ and $40 \mathrm{~mm} / \mathrm{h}$. The legend indicates the probability (frequency) of a certain orientation of a particular crystallographic axis. 